\title{
Osteosarcoma of the Pelvis
}

\section{Outcome Analysis of Surgical Treatment}

\author{
Bruno Fuchs MD, PhD, Nathan Hoekzema MD, \\ Dirk R. Larson MS, Carrie Y. Inwards MD, \\ Franklin H. Sim MD
}

Received: 27 December 2007 / Accepted: 20 August 2008/Published online: 15 October 2008

(C) The Association of Bone and Joint Surgeons 2008

\begin{abstract}
Risk factors to explain the poor survival of patients with osteosarcoma of the pelvis are poorly understood. Therefore, we attempted to identify factors affecting survival and development of local recurrence and metastasis. We retrospectively reviewed 43 patients who had high-grade pelvic tumors and were treated surgically. Twenty lesions were chondroblastic, 10 fibroblastic, 11 osteoblastic, and one each was giant cell-rich and small cell osteosarcomas. At a median of 3.5 years (range, 0.321 years) postoperatively, 13 patients were alive with no evidence of disease. The overall and disease-free 5-year
\end{abstract}

Each author certifies that he or she has no commercial associations (eg, consultancies, stock ownership, equity interest, patent/licensing arrangements, etc) that might pose a conflict of interest in connection with the submitted article.

Each author certifies that his or her institution has approved the reporting of these cases, that all investigations were conducted in conformity with ethical principles of research, and that informed consent for participation in the study was obtained.

\section{B. Fuchs $(\square)$}

Division of Orthopedic Oncology, Department of Orthopedics, Balgrist University Hospital, University of Zurich, Forchstrasse 340, 8008 Zurich, Switzerland

e-mail: bruno.fuchs@balgrist.ch

\section{N. Hoekzema, F. H. Sim}

Division of Orthopedic Oncology, Mayo Clinic, Rochester, MN, USA

D. R. Larson

Department of Biostatistics, Mayo Clinic, Rochester, MN, USA

C. Y. Inwards

Department of Surgical Pathology, Mayo Clinic, Rochester, MN, USA survival rates were $38 \%$ and $29 \%$, respectively, at 5 years. Anatomic location, tumor size, and margin predicted survival. Fifteen patients (35\%) had local recurrence. The 5 -year cumulative incidence of recurrence with death as a competing risk factor was $34 \%$. Location in the ilium and size of the tumor predicted local recurrence. Twenty-one $(49 \%)$ of 43 patients had metastases develop. The cumulative incidence of metastasis with death as a competing risk factor was $48 \%$ at 5 years. Six patients who presented with metastasis had a worse survival than patients who had no evidence of metastasis at presentation (2-year survival, $33 \%$ versus $76 \%$ ). If distant metastasis is diagnosed subsequent to primary treatment, aggressive therapy may be justified.

Level of Evidence: Level II, prognostic study. See the Guidelines for Authors for a complete description of levels of evidence.

\section{Introduction}

Treating malignant tumors of the pelvis is one of the most challenging problems for the orthopaedic oncologist $[5,22]$. Osteosarcoma of the pelvis accounts for $4 \%$ to $10 \%$ of all osteosarcomas $[12,21]$. These tumors are difficult to resect because of their location, local extension, and large size, and because of the complex regional and local anatomy and the difficulty in establishing functional reconstructions that are durable and allow patients maximum function. Affected patients reportedly have a poor outcome ranging from $4 \%$ to $32 \%[4,6,11,18,23,25]$, which is in stark contrast to the $70 \%$ to $75 \% 5$-year survival rate of patients with osteosarcoma of the extremities $[8,13$, 14], The reason for this poor outcome is severalfold. Often, there is a delay in diagnosis or a misdiagnosis, which 
usually is associated with a long duration of symptoms and which may lead already to metastases before establishing the diagnosis. Anatomically, there is poor compartmentalization in the pelvis because of the large size of these lesions; they may cross the sacroiliac joint or involve the pelvic veins [12]. This in turn makes it difficult to achieve a wide margin. Furthermore, pelvic osteosarcomas are often chondroblastic, a histologic subtype that responds only poorly to chemotherapy $[18,25]$.

In the six largest series of pelvic osteosarcomas, including between 25 and 67 patients, the 5-year survival rate ranged from $4 \%$ to $32 \%$ [4, 6, 11, 18, 23, 25]. The rate of secondary osteosarcomas in these series was as much as $33 \%$, which also may contribute to the poor prognosis of these patients. In the same series, the local recurrence rate reportedly was between $11 \%$ and $62 \%$, whereas the rate of metastases was between $23 \%$ and $80 \%$ [4, 6, 11, 18, 23, 25]. The type of surgery and indication to perform surgery for osteosarcoma of the pelvis may vary from institution to institution. This makes it difficult to compare large series to define prognostic parameters for this disease. Furthermore, the risk factors or factors that may be correlated with disease progression in patients with operable osteosarcomas of the pelvis are poorly understood.

We specifically asked (1) which risk factors affect survival, (2) which factors predict the rate of local recurrence, and (3) which factors predict metastasis.

\section{Materials and Methods}

We retrospectively reviewed the records of all 43 patients who underwent surgery for pelvic osteosarcomas at the Mayo Clinic between 1983 and 2003. Several clinical parameters were recorded and their influence on survival, local recurrence, and metastasis were statistically assessed. Seven patients we treated but who had previous surgical treatment before their initial visit were excluded from this review. Included in the study were 14 female patients and 29 male patients with a mean (standard deviation) age of 34.4 years (17.9 years) (range, 11-66 years) at the time of diagnosis. No patients were seen specifically for this review; none of our patients was lost to followup. After a minimum duration of followup of 0.3 year (mean, 4.8 years; range, 0.3-21 years; median, 3.5 years), 13 (31\%) patients were alive with no evidence of disease and $30(69 \%)$ patients had died. We focused our analysis primarily on survival and disease-free survival and secondarily on local recurrence and metastasis. We obtained prior Institutional Review Board approval.

The mean duration of symptoms was 6 months (range, 0-15 months). Sixteen osteosarcomas were located in the ilium, nine at the sacroiliac joint, 10 in the acetabulum, five in the ischium, two in the pubic bone, and one in the sacrum. Histologic analyses revealed 20 chondroblastic, 10 fibroblastic, 11 osteoblastic, and one each giant cell-rich and small cell osteosarcoma. All lesions were high-grade. The etiology of 33 osteosarcomas was considered primary, whereas 10 lesions were secondary, including one arising in Paget's disease and nine postirradiation osteosarcomas. Of these, there were four cervical cancers and one each lymphoma, rectal cancer, rhabdomyosarcoma of the prostate, primitive neuroectodermal tumor, and angiosarcoma, which initially were treated with radiation. The largest diameter of these lesions averaged $9.6 \mathrm{~cm}$ (standard deviation, $3.9 \mathrm{~cm}$; range, 4-22 cm). Overall, 19 tumors were $10 \mathrm{~cm}$ or larger.

Based on imaging, if critical structures were involved and an adequate margin could not be achieved, then hemipelvectomy was performed. If there was involvement of either the hip or the neurovascular structures, internal hemipelvectomy was performed, whereas when two or more of these structures were involved, external hemipelvectomy was done. We performed 29 (67\%) internal and $14(33 \%)$ external hemipelvectomies. We defined an adequate margin (whether wide or marginal) as one with a cuff of normal tissue around the tumor or one where the tumor was covered by fascia separated easily from the surrounding structures without any evidence of infiltration. By this definition an adequate margin was achieved in 30 patients. An inadequate margin (intralesional) occurred in 13 patients $(30 \%)$.

Followup included reevaluation of the patients at 3- to 4-month intervals for the first 2 years, at 6-month intervals for the next 3 years, and once a year after 5 years. Clinic visits were complemented by letters and questionnaires provided by our institutional cancer registry. The questionnaires were related to general but not functional information. For each patient, the etiology and size of the lesion, type of resection, surgical margins, anatomic location, histology, gender, age, radiotherapy, (neo)adjuvant chemotherapy (adriamycin, cisplatin, high-dose methotrexate), local recurrence, metastasis, disease status at the latest followup, and major complications associated with treatment were collected and analyzed for each patient. We (CYI) reviewed hematoxylin and eosin-stained sections from each tumor. The number of slides available for review ranged from four to 25 with a mean of 12 slides per case. The histologic subtype was classified as chondroblastic, osteoblastic, or fibroblastic and graded accordingly.

A power analysis was performed to determine the smallest hazard ratios that could be detected with $80 \%$ power among the potential risk factors studied. For the primary outcome of survival, given the number of deaths observed and the distribution of these events among the potential risk factors studied, the smallest hazard ratio that 
could be detected with at least $80 \%$ power ranged from 2.8 to 4.5. Likewise, for disease-free survival, the smallest hazard ratio that could be detected with at least $80 \%$ power ranged from 2.7 to 3.6. Therefore, analyses of potential risk factors with an observed hazard ratio less than 2.8 (for survival) or less than 2.7 (for disease-free survival) would be unlikely clinically important. Thus, the evaluations of some potentially important risk factors were underpowered.

The analysis focused on the primary outcomes of survival and disease-free survival, the latter defined as survival free of death, local recurrence, or metastasis. Additional outcomes included local recurrence and metastasis. Survival and disease-free survival rates for all 47 patients were estimated using the method of Kaplan and Meier [17]. The rates of local recurrence and metastasis were estimated by calculating the cumulative incidence of these outcomes accounting for the competing risk of death [10]. The effect of potential risk factors on survival and disease-free survival were evaluated using Cox proportional hazards models; the effects of local recurrence, metastasis, and either recurrence or metastasis were modeled as time-dependent covariates in the Cox models. To graphically display the time-dependent effect of recurrence or metastasis on survival, a landmark survival curve was generated. A landmark of 18 months was chosen, and patients were grouped according to whether they had local recurrence or metastasis within the first 18 months after surgery. The impact of potential risk factors on the outcomes of recurrence and metastasis was evaluated using a competing risk analysis in a Cox proportional hazards model $[10,19]$ accounting for the competing risk of death. Between-group comparisons of continuous nontime-toevent outcomes (such as tumor necrosis rate) were performed using Wilcoxon rank sum tests. All analyses were performed using SAS ${ }^{\circledR}$ Version 9.1 (SAS Institute Inc, Cary, NC) and S-PLUS ${ }^{\circledR}$ Version 8.0 (Insightful Corp, Seattle, WA).

\section{Results}

The overall survival rate of the entire group was $38 \%$ at 5 years and $32 \%$ at 10 years (Fig. 1; Table 1). Location of the lesion, recurrence, and metastasis were the most important factors adversely affecting survival (Table 2). Although tumor size of $10 \mathrm{~cm}$ or greater predicted survival in the univariate model, it did not predict survival in the multivariable model already containing tumor location and the advent of metastasis and/or local recurrence, thus confirming the primary importance of the latter variables relative to tumor size. We observed worse survival among patients with lesions located in the ilium versus other locations (hazard ratio, 2.4; $\mathrm{p}=0.03$ ) and metastasis alone

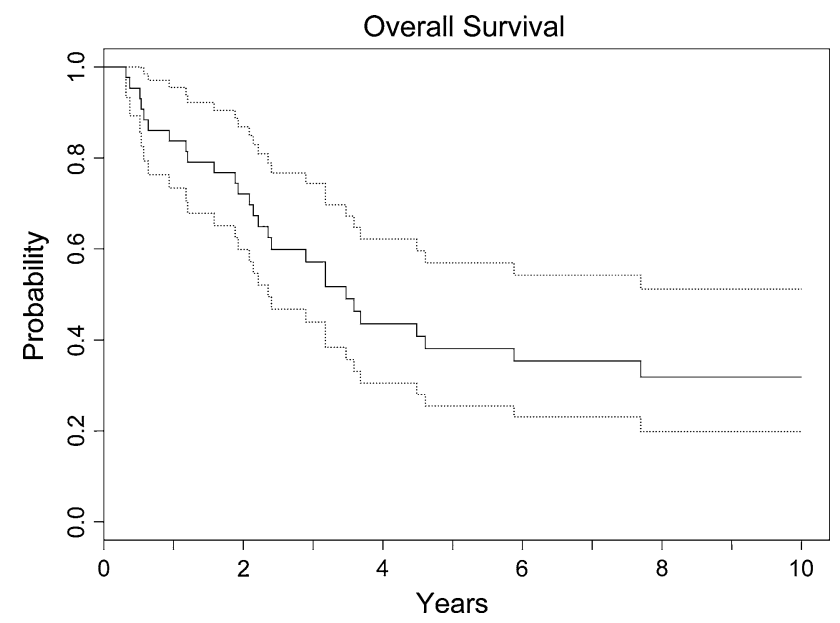

Fig. 1 This Kaplan-Meier curve shows overall survival of the entire group of patients who had surgery for an osteosarcoma of the pelvis. Patients were censored at last known followup. The dotted curves represent the $95 \%$ confidence interval. The 5-year survival rate of the entire group was $38 \%$. Location of the lesion, recurrence, and metastasis were the most important factors adversely affecting survival.

or in combination with local recurrence (hazard ratio, 11.9; $\mathrm{p}<0.001$ ) (Table 2). The hazard ratios for these variables in the multivariable model are similar to the hazard ratios for each variable univariately, suggesting adjusting for one or the other variable does not diminish the influence of the other. Patients who had local recurrence or metastasis within the first 18 months had worse $(\mathrm{p}=0.003)$ survival than those who did not (Fig. 2). The disease-free survival rate of the entire group was $29 \%$ at 5 years and $26 \%$ at 10 years (Fig. 3; Table 1). Although inadequate margin predicted survival when analyzed univariately, it did not predict survival in a model containing a tumor size equal to or greater than $10 \mathrm{~cm}$. However, our analysis confirmed tumor size of $10 \mathrm{~cm}$ or greater (hazard ratio, 3.2; $\mathrm{p}=0.004)$ is a major risk factor for poor disease-free survival (Table 3). Survival of patients with chondroblastic lesions was similar $(\mathrm{p}=0.22)$ to survival of patients with other types of lesions.

Tumor location and tumor size of $10 \mathrm{~cm}$ or greater were major risk factors for development of local recurrence. Fifteen $(35 \%)$ of the 43 patients had local recurrence. If a patient had a recurrence, none was alive at followup. The cumulative incidence of recurrence with death as a competing risk factor was 34\% (95\% confidence interval, 19\%$46 \%$ ) at 5 years, showing all recurrences developed within 3 years after surgery (Fig. 4; Tables 4, 5). When death was used as a competing risk factor, tumor location (ilium versus other locations; hazard ratio, $2.1 ; \mathrm{p}=0.05$ ) and tumor size of $10 \mathrm{~cm}$ or greater (hazard ratio, 2.8; $p=0.007)$ were identified as risk factors for the development of local recurrence. Of patients who had an 
Table 1. Survival and disease-free survival estimates

\begin{tabular}{lllllll}
\hline Outcome & Number & Events & 1-year rate* & 2-year rate & 5-year rate & 10-year rate \\
\hline Survival & 43 & 30 & $0.837(0.73-0.96)$ & $0.721(0.60-0.87)$ & $0.381(0.26-0.57)$ & $0.318(0.20-0.51)$ \\
Disease-free survival & 40 & 31 & $0.675(0.54-0.84)$ & $0.475(0.34-0.66)$ & $0.294(0.18-0.49)$ & $0.261(0.15-0.46)$ \\
\hline
\end{tabular}

* $95 \%$ confidence interval in parentheses.

Table 2. Survival by potential risk factor

\begin{tabular}{|c|c|c|c|c|c|c|}
\hline Factor & Level & Number & Events & Hazard ratio & $95 \%$ confidence interval & $\mathrm{p}$ Value \\
\hline \multirow[t]{2}{*}{ Gender } & Female & 14 & 9 & 1.00 & & \\
\hline & Male & 29 & 21 & 0.59 & $0.264-1.325$ & 0.20 \\
\hline \multirow[t]{2}{*}{ Age } & $<30$ years & 22 & 14 & 1.00 & & \\
\hline & $\geq 30$ years & 21 & 16 & 1.07 & $0.501-2.281$ & 0.86 \\
\hline \multirow{2}{*}{ Location } & Sacroiliac joint or other & 27 & 17 & 1.00 & & \\
\hline & Ilium & 16 & 13 & 2.32 & $1.083-4.982$ & 0.03 \\
\hline \multirow{2}{*}{ Location } & Ilium or other & 34 & 26 & 1.00 & & \\
\hline & Sacroiliac joint & 9 & 4 & 0.47 & $0.164-1.367$ & 0.17 \\
\hline \multirow[t]{2}{*}{ Location } & Ilium & 16 & 13 & 1.00 & & \\
\hline & Sacroiliac joint & 9 & 4 & 0.40 & $0.128-1.239$ & 0.11 \\
\hline \multirow{2}{*}{ Maximum tumor size } & $<10 \mathrm{~cm}$ & 24 & 12 & 1.00 & & \\
\hline & $\geq 10 \mathrm{~cm}$ & 19 & 18 & 2.63 & $1.255-5.518$ & 0.01 \\
\hline \multirow[t]{2}{*}{ Margins } & Adequate & 30 & 19 & 1.00 & & \\
\hline & Inadequate & 13 & 11 & 1.57 & $0.742-3.334$ & 0.24 \\
\hline \multirow[t]{2}{*}{ Histology } & Other & 23 & 16 & 1.00 & & \\
\hline & Chondroblastic & 20 & 14 & 0.62 & $0.287-1.321$ & 0.21 \\
\hline \multirow[t]{2}{*}{ Primary } & No & 10 & 8 & 1.00 & & \\
\hline & Yes & 33 & 22 & 0.75 & $0.329-1.708$ & 0.49 \\
\hline \multirow[t]{2}{*}{ Extent of procedure } & Internal & 29 & 19 & 1.00 & & \\
\hline & External & 14 & 11 & 1.05 & $0.499-2.224$ & 0.89 \\
\hline \multirow[t]{2}{*}{ Radiotherapy } & No & 32 & 21 & 1.00 & & \\
\hline & Yes & 11 & 9 & 1.59 & $0.716-3.515$ & 0.26 \\
\hline \multirow[t]{2}{*}{ Chemotherapy } & No & 7 & 5 & 1.00 & & \\
\hline & Yes & 36 & 25 & 2.00 & $0.73-5.475$ & 0.18 \\
\hline \multirow[t]{2}{*}{ Recurrence* } & No & & & 1.00 & & \\
\hline & Yes & & & 15.50 & $6.5-37.0$ & $<0.001$ \\
\hline \multirow[t]{2}{*}{ Metastasis* } & No & & & 1.00 & & \\
\hline & Yes & & & 5.20 & $2.4-11.3$ & $<0.001$ \\
\hline \multirow[t]{2}{*}{ Recurrence or metastasis* } & No & & & 1.00 & & \\
\hline & Yes & & & 11.40 & $4.5-28.9$ & $<0.001$ \\
\hline \multicolumn{7}{|l|}{ Multivariable analysis } \\
\hline Recurrence or metastasis* & Yes versus no & & & 11.90 & $4.7-30.0$ & $<0.001$ \\
\hline Location & Ilium versus other & & & 2.38 & $1.1-5.3$ & 0.03 \\
\hline
\end{tabular}

* Analyzed as a time-dependent covariate.

adequate surgical margin, seven of 30 patients (23\%) had recurrence, whereas of patients with an inadequate margin, eight of 13 patients $(62 \%)$ had recurrence. Although the hazard ratio for inadequate versus adequate margin was $1.99(\mathrm{p}=0.12)$, the parameter is probably not an important risk factor.
An inadequate margin and tumor size of $10 \mathrm{~cm}$ or greater were major risk factors for development of metastasis. Six patients presented with metastasis, and their survival was worse $(p=0.004)$ than those who presented with no evidence of metastasis (2-year survival, 33\% versus $76 \%$ ). Twenty-one (49\%) of 43 patients had subsequent 


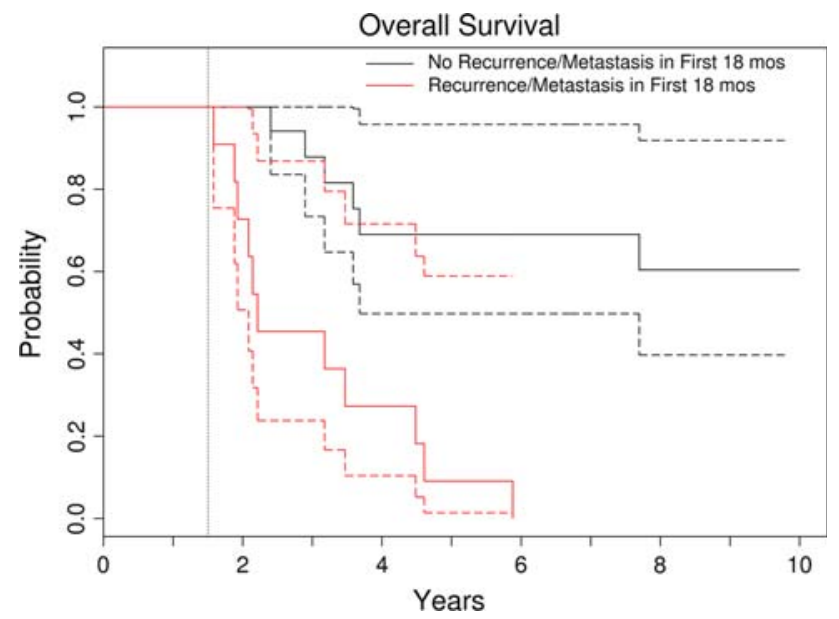

Fig. 2 This Kaplan-Meier survival curve shows overall survival using an 18-month landmark. Patients were grouped into those who had local recurrence or metastasis within the first 18 months and those who were free of recurrence or metastasis at 18 months. This is a graphic representation of the time-dependent effect of recurrence and metastasis on survival. The dotted curves represent the 95\% confidence intervals. Patients who had metastasis develop within the first 18 months had worse survival than those who did not.

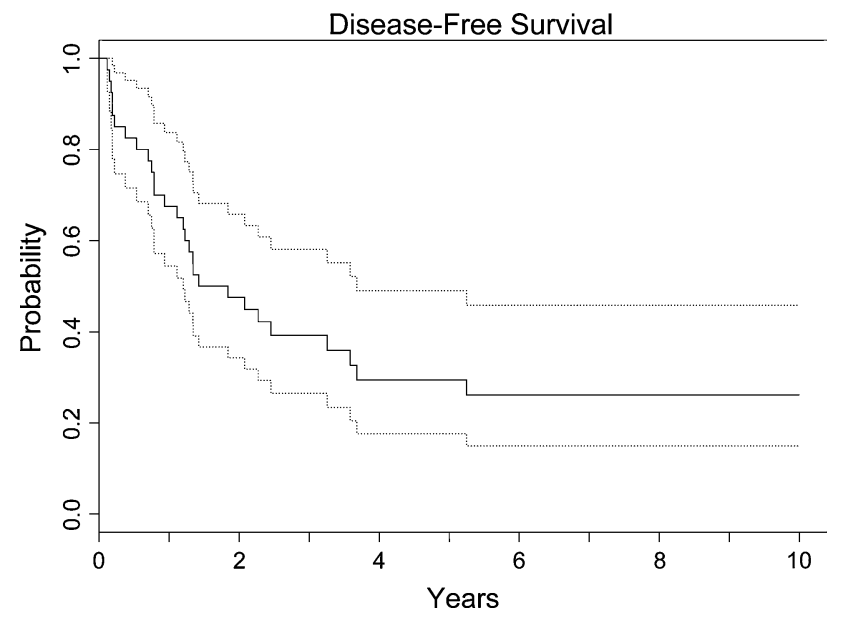

Fig. 3 This Kaplan-Meier curve shows the disease-free survival rate of the entire group. Patients were censored at last known followup. The dotted curves represent the $95 \%$ confidence interval. The diseasefree survival rate of the entire group was $29 \%$.

metastases. Eighteen (86\%) of 21 patients who had metastases were dead at the latest followup. The cumulative incidence of metastasis with death as a competing risk factor was $48 \%$ (95\% confidence interval, $32 \%-61 \%$ ) at 5 years. Most of the metastases developed within 3 years after surgery (Fig. 5; Table 4). Tumor size of $10 \mathrm{~cm}$ or greater (hazard ratio, 2.9; $\mathrm{p}=0.005$ ) and an inadequate margin (hazard ratio, 2.0; $\mathrm{p}=0.06$ ) were important risk factors for metastasis with death as a competing risk factor (Table 6).

The mean tumor necrosis rate was $37.5 \%$ (standard deviation, 35\%; range, $0 \%-100 \%$ ). As expected, the necrosis rate was lower $(\mathrm{p}=0.22)$ for chondroblastic lesions (mean, 27\%; standard deviation, 27.3\%; range, $0 \%-98 \%$ ) than for other types of lesions (mean, 47\%; standard deviation, $39.2 \%$; range, $0 \%-100 \%$ ).

Infection and local wound breakdown were the most common complications that required débridement in 14 patients. One each colostomy and ileostomy and two cystectomies were necessary because of lacerations during the index surgery. There was one compartment syndrome of the hand, which required decompression, a pseudomeningocele, and a stroke and heart failure subsequent to chemotherapy in one patient each.

\section{Discussion}

The overall survival of patients with an osteosarcoma of the pelvis is considered to be poorer than that of patients with extremity osteosarcoma. To improve the outcome of these patients, risk factors need to be identified. A few patients with pelvic osteosarcoma may be inoperable and therefore may have a poorer prognosis per se. If these patients are not separated from patients with operable lesions and potentially better prognoses, we may reach confounded conclusions. Our study therefore focuses on patients with osteosarcoma of the pelvis with operable lesions. We identified (1) which among a number of risk factors influenced survival, (2) which factors predicted the rate of local recurrence, and (3) which factors predicted metastasis.

Limitations of our study include the retrospective nature of our analysis assessing patients during a 20-year period. During this time, surgical techniques evolved, and improved imaging modalities such as CT and MRI allowed precise delineation of the tumor from the surrounding anatomic structures, which resulted in improved treatment during the latter period of the study. Another limitation is, given the size of the patient cohort and the number of observed deaths, the power to detect differences was low for some of the parameters studied. Therefore, the reader needs to be aware, even in case of statistical significance, the identified risk factors may not imply causal relationship but only a correlation. However, these are uncommon tumors and it is difficult to accumulate a large series from one institution.

Our 5-year survival rate was $38 \%$ and at the high end of comparable series in which it ranges from $4 \%$ to $32 \%[4,6$, $11,18,23,25]$. One explanation may be the comparably lower local recurrence rate in this series and that we included only patients who were operated on with a curative rather than palliative intent. Nevertheless, our results suggest the survival of patients with pelvic osteosarcomas is not comparable to the survival of patients with extremity 
Table 3. Disease-free survival by potential risk factor*

\begin{tabular}{|c|c|c|c|c|c|c|}
\hline Factor & Level & Number & Events & Hazard ratio & $95 \%$ confidence interval & $\mathrm{p}$ Value \\
\hline \multirow[t]{2}{*}{ Gender } & Female & 13 & 8 & 1.00 & & \\
\hline & Male & 27 & 23 & 1.02 & $0.449-2.321$ & 0.96 \\
\hline \multirow[t]{2}{*}{ Age } & $<30$ years & 21 & 15 & 1.00 & & \\
\hline & $\geq 30$ years & 19 & 16 & 1.16 & $0.547-2.466$ & 0.70 \\
\hline \multirow[t]{2}{*}{ Location } & Sacroiliac joint or other & 25 & 18 & 1.00 & & \\
\hline & Ilium & 15 & 13 & 1.65 & $0.782-3.474$ & 0.19 \\
\hline \multirow[t]{2}{*}{ Location } & Ilium or other & 32 & 26 & 1.00 & & \\
\hline & Sacroiliac joint & 8 & 5 & 0.92 & $0.348-2.417$ & 0.86 \\
\hline \multirow[t]{2}{*}{ Location } & Ilium & 15 & 13 & 1.00 & & \\
\hline & Sacroiliac joint & 8 & 5 & 0.72 & $0.254-2.025$ & 0.53 \\
\hline \multirow[t]{2}{*}{ Maximum tumor size } & $<10 \mathrm{~cm}$ & 21 & 12 & 1.00 & & \\
\hline & $\geq 10 \mathrm{~cm}$ & 19 & 19 & 3.19 & $1.465-6.961$ & 0.004 \\
\hline \multirow[t]{2}{*}{ Margins } & Adequate & 27 & 19 & 1.00 & & \\
\hline & Inadequate & 13 & 12 & 2.24 & $1.06-4.731$ & 0.03 \\
\hline \multirow[t]{2}{*}{ Histology } & Other & 20 & 15 & 1.00 & & \\
\hline & Chondroblastic & 20 & 16 & 0.82 & $0.392-1.7$ & 0.59 \\
\hline \multirow[t]{2}{*}{ Primary } & No & 8 & 7 & 1.00 & & \\
\hline & Yes & 32 & 24 & 0.75 & $0.317-1.768$ & 0.51 \\
\hline \multirow[t]{2}{*}{ Extent of procedure } & Internal & 26 & 19 & 1.00 & & \\
\hline & External & 14 & 12 & 1.34 & $0.638-2.802$ & 0.44 \\
\hline \multirow[t]{2}{*}{ Radiotherapy } & No & 29 & 21 & 1.00 & & \\
\hline & Yes & 11 & 10 & 1.30 & $0.603-2.795$ & 0.50 \\
\hline \multirow[t]{2}{*}{ Chemotherapy } & No & 7 & 5 & 1.00 & & \\
\hline & Yes & 33 & 26 & 3.86 & $0.912-16.293+\mathrm{F} 2$ & 0.07 \\
\hline
\end{tabular}

* After accounting for maximum tumor size $10 \mathrm{~cm}$ or greater, no other variables contributed substantially in the multivariable analysis of disease-free survival.

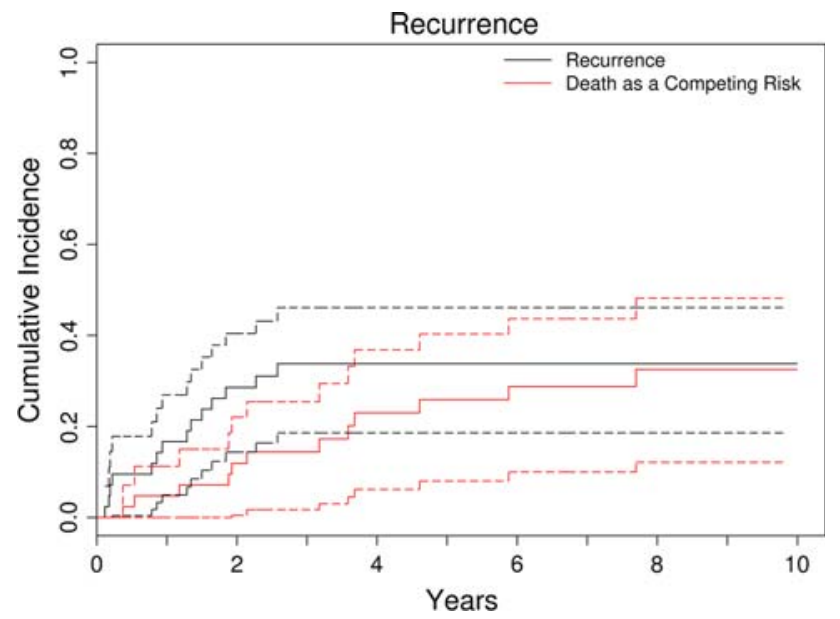

Fig. 4 The cumulative incidence of recurrence is represented over time with death as a competing risk. The dotted curves represent the 95\% confidence intervals. The cumulative incidence of recurrence rate was $34 \%$, and they all occurred within 3 years after surgery. Tumor location and tumor size of $10 \mathrm{~cm}$ or greater were major risk factors for development of local recurrence. lesions. Another reason for the poorer survival may be the high rate of metastasis. In our series, $18 \%$ of all patients were diagnosed with lung metastasis at initial presentation, and $56 \%$ of all patients had metastasis develop during the course of followup. This is comparable to other series reporting an incidence between $26 \%$ and $63 \%$ [20, 25]. Several factors that may be responsible for metastasis have been discussed, including surgical stage, histologic subtype, and type of surgical treatment. The high incidence of metastasis at diagnosis is also comparable to that reported by others $[2,12,23,25,28]$, who noted osteosarcomas of the trunk are more likely to have metastasized at diagnosis than tumors of the extremity. Also reported by others [20], the efficacy of chemotherapy was not a prognostic factor in our series. Therefore, chemotherapy alone may not hinder the development of metastasis in high-grade tumors of the pelvis. As expected, patients without metastases had a better 5-year survival rate than patients with metastases. We further separated the patient group who had metastasis develop into those who presented with or had metastasis develop during initial treatment (neoadjuvant therapy, 
Table 4. Cumulative incidence of recurrence and metastasis with death as a competing risk

\begin{tabular}{lclll}
\hline Outcome & 1-year rate* & 2-year rate* & 5-year rate* & 10-year rate* \\
\hline Recurrence & $0.167(0.05-0.27)$ & $0.286(0.14-0.40)$ & $0.338(0.19-0.46)$ & $0.338(0.19-0.46)$ \\
Death (competing risk) & $0.048(0.00-0.11)$ & $0.119(0.00-0.22)$ & $0.259(0.08-0.40)$ & $0.325(0.12-0.48)$ \\
Metastasis & $0.22(0.09-0.33)$ & $0.366(0.21-0.49)$ & $0.481(0.32-0.61)$ & $0.512(0.34-0.64)$ \\
Death (competing risk) & $0.073(0-0.15)$ & $0.098(0-0.19)$ & $0.243(0.04-0.4)$ & $0.243(0.04-0.4)$ \\
\hline
\end{tabular}

* $95 \%$ confidence interval in parentheses.

Table 5. Recurrence with death as a competing risk by potential risk factor

\begin{tabular}{|c|c|c|c|c|}
\hline Factor & Level & $\begin{array}{l}\text { Hazard } \\
\text { ratio }\end{array}$ & $\begin{array}{l}95 \% \\
\text { confidence } \\
\text { interval }\end{array}$ & $\mathrm{p}$ Value \\
\hline \multirow[t]{2}{*}{ Gender } & Female & 1.00 & & \\
\hline & Male & 0.68 & $0.28-1.69$ & 0.41 \\
\hline \multirow[t]{2}{*}{ Age } & $<30$ years & 1.00 & & \\
\hline & $\geq 30$ years & 1.06 & $0.49-2.26$ & 0.89 \\
\hline \multirow[t]{2}{*}{ Location } & $\begin{array}{l}\text { Sacroiliac } \\
\text { joint or other }\end{array}$ & 1.00 & & \\
\hline & Ilium & 2.09 & $1-4.37$ & 0.05 \\
\hline \multirow[t]{2}{*}{ Location } & Ilium or other & 1.00 & & \\
\hline & Sacroiliac joint & 0.51 & $0.15-1.73$ & 0.28 \\
\hline \multirow[t]{2}{*}{ Location } & Ilium & 1.00 & & \\
\hline & Sacroiliac joint & 0.46 & $0.15-1.46$ & 0.19 \\
\hline \multirow{2}{*}{$\begin{array}{l}\text { Maximum } \\
\text { tumor size }\end{array}$} & $<10 \mathrm{~cm}$ & 1.00 & & \\
\hline & $\geq 10 \mathrm{~cm}$ & 2.75 & $1.31-5.77$ & 0.007 \\
\hline \multirow[t]{2}{*}{ Margins } & Adequate & 1.00 & & \\
\hline & Inadequate & 1.99 & $0.84-4.67$ & 0.12 \\
\hline \multirow[t]{2}{*}{ Histology } & Other & 1.00 & & \\
\hline & Chondroblastic & 0.73 & $0.34-1.53$ & 0.4 \\
\hline \multirow[t]{2}{*}{ Primary } & No & 1.00 & & \\
\hline & Yes & 0.81 & $0.36-1.85$ & 0.62 \\
\hline \multirow{2}{*}{$\begin{array}{l}\text { Extent of } \\
\text { procedure }\end{array}$} & Internal & 1.00 & & \\
\hline & External & 1.14 & $0.55-2.35$ & 0.72 \\
\hline \multirow[t]{2}{*}{ Radiotherapy } & No & 1.00 & & \\
\hline & Yes & 1.53 & $0.73-3.17$ & 0.26 \\
\hline \multirow[t]{2}{*}{ Chemotherapy } & No & 1.00 & & \\
\hline & Yes & 2.01 & $0.99-4.08$ & 0.052 \\
\hline
\end{tabular}

surgery, adjuvant therapy) and those who metastasis develop subsequently. Our analysis showed patients with metastasis present at diagnosis fared worse than patients who had metastases develop after completion of treatment. This also was described for patients with osteosarcoma of the extremity [1]. This has several important consequences. First, the similar biologic behavior with respect to metastasis between extremity and axial osteosarcomas implies these tumors, as often questioned, share the same biology, regardless of their different survival. Therefore, we believe there must be other parameters that account for the survival

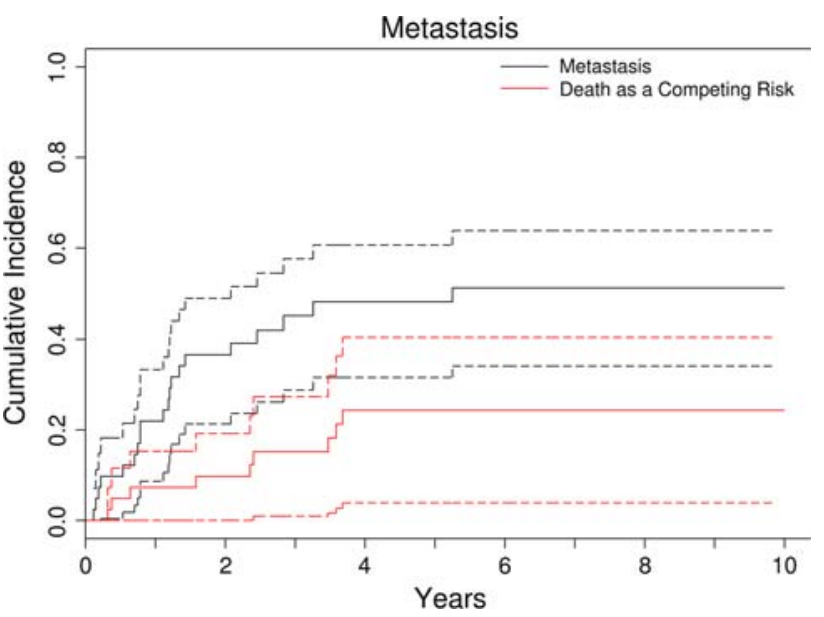

Fig. 5 The cumulative incidence of metastasis is represented with death as a competing risk factor. The dotted curves represent the $95 \%$ confidence intervals. The cumulative incidence rate of metastasis was $48 \%$, and the majority occurred within 3 years. An inadequate margin and tumor size of $10 \mathrm{~cm}$ or greater were major risk factors for development of metastasis.

disadvantage of patients with pelvic compared with extremity osteosarcomas. Second, our results reveal, if metastasis is diagnosed subsequent to initial treatment, the prognosis is not fatal and may require aggressive combined treatments because four of these patients in our series survived.

We found tumor size, represented by the greatest tumor dimension, predicted outcome and was negatively associated with the development of local recurrence and metastasis. Nineteen patients $(44 \%)$ had a tumor that was $10 \mathrm{~cm}$ or larger. This also may be reflected in the long duration of symptoms until the diagnosis was established, which averaged 6 months. This is longer than reported by Ozaki et al. [23] (3.7 months), Bielack et al. (2.3 months) [1], and Pollock et al. (1.9 months) [24]. Whereas in our study and another [27], size was a major negative predictor of outcome. Saab et al. [25] could not confirm this finding, probably because of the small number of patients included in their study. Because of the poor compartmentalization in the pelvis, large tumors often have extraosseous extension into gluteal muscles and/or involvement of the sciatic notch area, which requires transection of the gluteal or internal 
Table 6. Metastasis with death as a competing risk by potential risk factor

\begin{tabular}{|c|c|c|c|c|}
\hline Factor & Level & $\begin{array}{l}\text { Hazard } \\
\text { ratio }\end{array}$ & $\begin{array}{l}95 \% \\
\text { confidence } \\
\text { interval }\end{array}$ & $\mathrm{p}$ Value \\
\hline \multirow[t]{2}{*}{ Gender } & Female & 1.00 & & \\
\hline & Male & 0.96 & $0.42-2.21$ & 0.92 \\
\hline \multirow[t]{2}{*}{ Age } & $<30$ years & 1.00 & & \\
\hline & $\geq 30$ years & 1.20 & $0.57-2.5$ & 0.63 \\
\hline \multirow[t]{2}{*}{ Location } & $\begin{array}{l}\text { Sacroiliac } \\
\text { joint or other }\end{array}$ & 1.00 & & \\
\hline & Ilium & 1.67 & $0.85-3.28$ & 0.14 \\
\hline \multirow[t]{2}{*}{ Location } & Ilium or other & 1.00 & & \\
\hline & Sacroiliac joint & 0.95 & $0.34-2.66$ & 0.92 \\
\hline \multirow[t]{2}{*}{ Location } & Ilium & 1.00 & & \\
\hline & Sacroiliac joint & 0.72 & $0.24-2.13$ & 0.55 \\
\hline \multirow{2}{*}{$\begin{array}{l}\text { Maximum } \\
\text { tumor size }\end{array}$} & $<10 \mathrm{~cm}$ & 1.00 & & \\
\hline & $\geq 10 \mathrm{~cm}$ & 2.85 & $1.38-5.9$ & 0.005 \\
\hline \multirow[t]{2}{*}{ Margins } & Adequate & 1.00 & & \\
\hline & Inadequate & 2.00 & $0.96-4.15$ & 0.06 \\
\hline \multirow[t]{2}{*}{ Histology } & Other & 1.00 & & \\
\hline & Chondroblastic & 0.76 & $0.38-1.53$ & 0.44 \\
\hline \multirow[t]{2}{*}{ Primary } & No & 1.00 & & \\
\hline & Yes & 0.73 & $0.32-1.64$ & 0.44 \\
\hline \multirow{2}{*}{$\begin{array}{l}\text { Extent of } \\
\text { procedure }\end{array}$} & Internal & 1.00 & & \\
\hline & External & 1.37 & $0.68-2.76$ & 0.38 \\
\hline \multirow[t]{2}{*}{ Radiotherapy } & No & 1.00 & & \\
\hline & Yes & 1.32 & $0.66-2.62$ & 0.43 \\
\hline \multirow[t]{2}{*}{ Chemotherapy } & No & 1.00 & & \\
\hline & Yes & 3.73 & $0.79-17.64$ & 0.10 \\
\hline
\end{tabular}

iliac vessels. This in turn may contribute to the high rate of wound healing problems and infections as noted in our patients. Widespread invasion into major pelvic veins is reportedly a negative prognostic factor [6] but another study found seven patients (of 40) with emboli in the regional large vessels with a particularly poor prognosis [18]. We did not routinely perform angiography and intraoperatively we did not look for vascular invasion because we performed external hemipelvectomy.

The goal of surgery is to achieve a wide margin. However, because of the complex anatomy of the pelvis, including the close association of large vessels and nerves aligned in a complex manner around important visceral organs with poor compartmentalization, this is difficult to achieve. The overall local recurrence rate in our series was $34 \%$, which is comparable to rates reported in other studies $[6,18,20,23]$. This may be surprising because all patients included in our study were treated with a locally curative intent. In accordance with those reported studies, surgical margin was also a predictor of local recurrence. All patients who had local recurrence in our study were dead at the latest followup. Numerous authors have reported sacral involvement of the primary tumor or an ilium lesion crossing the sacroiliac joint is the most important predictor of development of local recurrences $[3,5,6,11,12,18$, 26]. Our results confirm these findings only partly because this anatomic location was not a major predictor for the development of local recurrence and/or metastasis. However, the ilium was a negative predictor of overall survival. Moreover, our results imply it is possible to achieve adequate margins in this difficult pelvic area, which is in line with a previous report from our institution [9]. Internal hemipelvectomy has become more popular than classic external hemipelvectomy [15, 23]. As others have shown, the survival of patients who underwent either external or internal hemipelvectomy did not differ in our series [4]. As a consequence, considering the risk of death after local recurrence, external hemipelvectomy may be chosen for patients in whom limb-salvage surgery may be associated with an inadequate surgical margin.

In 20 patients $(46 \%)$, the tumor histology was chondroblastic. The high incidence of this histologic subtype is consistent with the observation of others that the chondroblastic subtype has a greater tendency to involve the trunk $[2,12,18]$, with $36 \%$ to $58 \%$ of pelvic osteosarcomas being chondroblastic. This is in contrast to reported series for osteosarcoma of the extremities, in which the majority of tumors are osteoblastic [25]. There were many secondary pelvic osteosarcomas in our series, which parallels the findings of Grimer et al. [11] and Saab et al. [25], who found an incidence of $33 \%$ and $21 \%$, respectively, in their series. This is higher than the $4 \%$ incidence of irradiation-related osteosarcomas reported for all sites [7]. Irradiation-associated osteosarcoma and osteosarcomatous transformation in Paget's disease or fibrous dysplasia generally were associated with poorer prognosis [7]. Whereas Grimer et al. [11] reported none of their patients with secondary osteosarcoma was alive after 29 months, we were not able to detect a difference in our series between the survival of patients with primary versus secondary tumors. Based on our results and others [1, 25], we believe, provided local tumor control is achieved and adjuvant therapy applied, these patients may have a prognosis similar to that of patients with otherwise comparable primary osteosarcoma [16].

The overall survival rate of patients with osteosarcoma of the pelvis does not reach the survival rate of patients with extremity osteosarcomas. Anatomic location, local recurrence, and metastasis are adverse parameters of survival. The size of the lesion negatively influenced the occurrence of metastasis and local recurrence, whereas an inadequate margin was important for development of metastasis, and anatomic location was an important predictor for development of local recurrence. Patients with 
local recurrence and the presence of metastasis at diagnosis have a poor outcome; patients diagnosed with metastasis subsequent to treatment or without metastasis have a better survival rate and aggressive adjuvant therapy may be justified.

\section{References}

1. Bielack SS, Kempf-Bielack B, Delling G, Exner GU, Flege S, Helmke K, Kotz R, Salzer-Kuntschik M, Werner M, Winkelmann W, Zoubek A, Jurgens H, Winkler K. Prognostic factors in highgrade osteosarcoma of the extremities or trunk: an analysis of 1,702 patients treated on neoadjuvant cooperative osteosarcoma study group protocols. J Clin Oncol. 2002;20:776-790.

2. Bielack SS, Wulff B, Delling G, Gobel U, Kotz R, Ritter J, Winkler K. Osteosarcoma of the trunk treated by multimodal therapy: experience of the Cooperative Osteosarcoma study group (COSS). Med Pediatr Oncol. 1995;24:6-12.

3. Campanacci M, Ruggieri P. Osteosarcoma. Bull Hosp Jt Dis Orthop Inst. 1991;51:1-11.

4. Donati D, Giacomini S, Gozzi E, Ferrari S, Sangiorgi L, Tienghi A, DeGroot H, Bertoni F, Bacchini P, Bacci G, Mercuri M. Osteosarcoma of the pelvis. Eur J Surg Oncol. 2004;30:332-340.

5. Enneking WF, Dunham WK. Resection and reconstruction for primary neoplasms involving the innominate bone. J Bone Joint Surg Am. 1978;60:731-746.

6. Fahey M, Spanier SS, Vander Griend RA. Osteosarcoma of the pelvis: a clinical and histopathological study of twenty-five patients. J Bone Joint Surg Am. 1992;74:321-330.

7. Frassica FJ, Sim FH, Frassica DA, Wold LE. Survival and management considerations in postirradiation osteosarcoma and Paget's osteosarcoma. Clin Orthop Relat Res. 1991;270:120-127.

8. Fuchs B, Pritchard DJ. Etiology of osteosarcoma. Clin Orthop Relat Res. 2002;397:40-52.

9. Fuchs B, Yaszemski MJ, Sim FH. Combined posterior pelvis and lumbar spine resection for sarcoma. Clin Orthop Relat Res. 2002;397:12-18.

10. Gooley TA, Leisenring W, Crowley J, Storer BE. Estimation of failure probabilities in the presence of competing risks: new representations of old estimators. Stat Med. 1999;18:695-706.

11. Grimer RJ, Carter SR, Tillman RM, Spooner D, Mangham DC, Kabukcuoglu Y. Osteosarcoma of the pelvis. J Bone Joint Surg Br. 1999;81:796-802.

12. Ham SJ, Kroon HM, Koops HS, Hoekstra HJ. Osteosarcoma of the pelvis: oncological results of 40 patients registered by The Netherlands Committee on Bone Tumours. Eur J Surg Oncol. 2000;26:53-60
13. Hayden JB, Hoang BH. Osteosarcoma: basic science and clinical implications. Orthop Clin North Am. 2006;37:1-7.

14. Hugate RR, Wilkins RM, Kelly CM, Madsen W, Hinshaw I, Camozzi AB. Intraarterial chemotherapy for extremity osteosarcoma and MFH in adults. Clin Orthop Relat Res. 2008;466:12921301.

15. Huth JF, Eckardt JJ, Pignatti G, Eilber FR. Resection of malignant bone tumors of the pelvic girdle without extremity amputation. Arch Surg. 1988;123:1121-1124.

16. Inoue YZ, Frassica FJ, Sim FH, Unni KK, Petersen IA, McLeod RA. Clinicopathologic features and treatment of postirradiation sarcoma of bone and soft tissue. J Surg Oncol. 2000;75:42-50.

17. Kaplan EL, Meier P. Nonparametric estimation from incomplete observations. J Am Stat Assoc. 1958;53:457-481.

18. Kawai A, Huvos AG, Meyers PA, Healey JH. Osteosarcoma of the pelvis: oncologic results of 40 patients. Clin Orthop Relat Res. 1998;348:196-207.

19. Lunn M, McNeil D. Applying Cox regression to competing risks. Biometrics. 1995;51:524-532.

20. Matsuo T, Sugita T, Sato K, Hotta T, Tsuchiya H, Shimose S, Kubo T, Ochi M. Clinical outcomes of 54 pelvic osteosarcomas registered by Japanese Musculoskeletal Oncology Group. Oncology. 2005;68:375-381.

21. Meyers PA, Gorlick R. Osteosarcoma. Pediatr Clin North Am. 1997;44:973-989.

22. O'Connor MI, Sim FH. Salvage of the limb in the treatment of malignant pelvic tumors. J Bone Joint Surg Am. 1989;71:481494.

23. Ozaki T, Flege S, Kevric M, Lindner N, Maas R, Delling G, Schwarz R, von Hochstetter AR, Salzer-Kuntschik M, Berdel WE, Jurgens H, Exner GU, Reichardt P, Mayer-Steinacker R, Ewerbeck V, Kotz R, Winkelmann W, Bielack SS. Osteosarcoma of the pelvis: experience of the Cooperative Osteosarcoma Study Group. J Clin Oncol. 2003;21:334-341.

24. Pollock BH, Krischer JP, Vietti TJ. Interval between symptom onset and diagnosis of pediatric solid tumors. J Pediatr. 1991;119:725-732.

25. Saab R, Rao BN, Rodriguez-Galindo C, Billups CA, Fortenberry TN, Daw NC. Osteosarcoma of the pelvis in children and young adults: the St Jude Children's Research Hospital experience. Cancer. 2005;103:1468-1474.

26. Shin KH, Rougraff BT, Simon MA. Oncologic outcomes of primary bone sarcomas of the pelvis. Clin Orthop Relat Res. 1994;304:207-217.

27. Taylor WF, Ivins JC, Dahlin DC, Edmonson JH, Pritchard DJ. Trends and variability in survival from osteosarcoma. Mayo Clin Proc. 1978;53:695-700.

28. Wurtz LD, Peabody TD, Simon MA. Delay in the diagnosis and treatment of primary bone sarcoma of the pelvis. $J$ Bone Joint Surg Am. 1999;81:317-325. 